\title{
AUTOMATIC PRODUCTION SYSTEM FOR CIRCUIT BOARDS WITH UNIVERSAL HYBRID INTEGRATED CIRCUITS
}

\author{
MITSUO OHSAWA \\ Sony Corporation, Tokyo, Japan
}

\begin{abstract}
In the 1970's, much development occurred in monolithic IC's and automatic insertion machines, which brought about extensive changes among mass producers of electronic consumer products and greatly influenced the improvement of quality and the saving of labor in production. The challenges of the next era are the achievement of the following four objectives in addition to the quality improvement and labor saving objectives involved in the recent decade. 1) The efficient use of material resources to eliminate waste, 2) elevation of reliability, 3) striving for uniform specifications for components on a worldwide basis to achieve more rational and efficient operations, and 4) the creation of unique products through new mounting and assembly techniques. Towards these objectives, a unique technology has been developed which has been named 'universal hybrid integrated circuits' (UHIC), for which the automatic production system has been put into practical use. The various components used in assembling through this system are cylindrical in shape and entirely new in concept. They are called 'metal electrode facebonding' (MELF) type components. The new production system has the capacity of mounting 600 components simultaneously and can handle circuit boards up to a size of 330 millimeters per side. This means that a stereo unit or a color television set can easily be assembled on one circuit board, which could be called "all-in-one UHIC".
\end{abstract}

\section{INTRODUCTION}

In 1970, ten years ago, while designing monolithic IC circuitry, consideration was given to methods of dealing with circuits that could not be integrated into IC's. Among the effective steps considered, the most popular method was the printing of resistors on an aluminaceramic circuit board, mounting transistors and ceramic capacitors on the board, and protecting the assembly with resin. However, cost and reliability were factors that were still in question. The aim, therefore, was to arrive at techniques that could be used not only in certain specific models of products but also in products at all grade levels and categories. With this in mind, the first concept was the use of an organic substrate for the circuit board and the mounting of stable component elements on the board instead of printing such elements. Printing would not have been adequately stable during heat treatment or in mechanical dimensions. Photo 1 shows the circuit board used in the TA-1150 Integrated Power Amplifier (produced in 1972). The circuit board was first printed with solder-resistant material, and solder cream was screen-printed on the portions of the circuit where the hybrid components were to be connected. Cylindrical resistors were dropped on the board, where they were temporarily held in place by the solder cream. The assembly was passed through a hot-air furnace, where the solder melted and bonded the connections, and then the entire board was washed. This was followed by a protective coating of epoxy resin on the components.

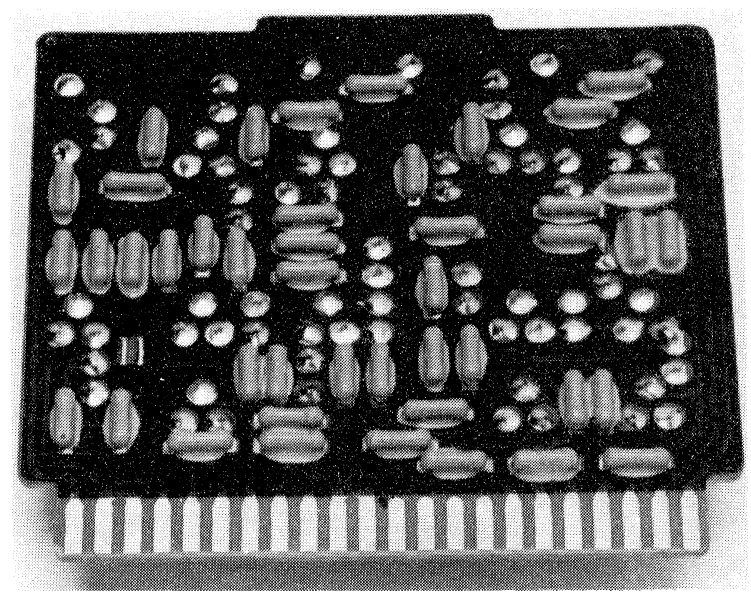

PHOTO 1 Module type produced in 1972 for TA-1150 Integrated Power Amplifier (SONY) 


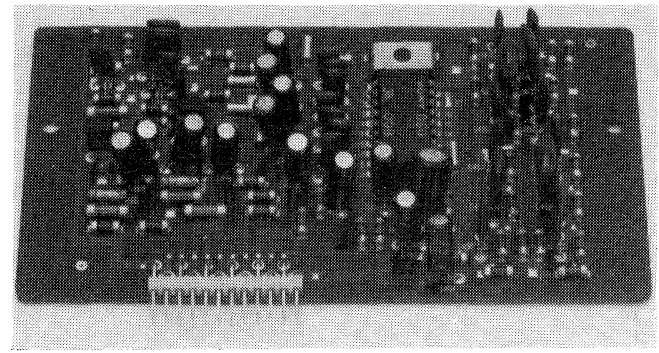

PHOTO 2 Module type produced in 1974 for FQ-6000 floor-type stereo (SONY).

This probably was one of the earliest examples of a hybrid IC simultaneously mounted by a machine on an organic circuit board. However, the components were large (2.5 $\mathrm{mm} \phi, 8.0 \mathrm{~mm}$ long) which limited the degree of integration density, and the components were restricted to resistors. The production process was complex. These reasons limited the use of this method to only about two or three years. However, the knowhow obtained during this time and the concepts directed towards the future were very useful in the developments leading to the present.

The second type was developed in 1974. By that time, IC's were being widely used in products, and circuit boards were designed to accommodate the peripherals of large-scale IC's (see Photo 2). The resistors were reduced in size to $2.2 \mathrm{~mm} \phi$ and $5.9 \mathrm{~mm}$ in length. Also for the first time, ceramic capacitors were made into cylindrical form of approximately the same outside shape. The process was nearly the same as before, but the flow soldering of the IC's and general components having leads was carried out on the side of the board underneath the components to protect them from the heat and where the copper foil circuit pattern had been produced on the board. The inner surface of the holes for the leads had been plated in advance, so that the molten solder would rise up osmotically to bond firmly the connections of the leads with the copper foil circuit pattern.

Through these two experiences, the points of challenge were

1) simplifying drastically the entire process, while improving the economy and increasing reliability,

2) arriving at a uniform shape for components covering a radically wide range of types,

3) developing components that would be tough mechanically and resistant to heat, while being easy to handle, and

4) creating an assembly structure that would be easy to repair and would also avoid the need to replace the entire circuit board when larger scale HIC's were adopted in the future.

In this period, automatic insertion machines were being increasingly adopted in production plants. However, the conviction that resources must be more efficiently used and that labor-saving, high-speed production systems were necessary pointed to the idea that lead wires on ordinary components and the taping and reels required for insertion machines were basically not needed.

The reasons for paying so much attention to $\mathrm{HIC}$ technology at present are that the appropriate application of this technology should be an effective means of achieving major break-throughs in existing production processes, and also that the technology can play an important role in supplementing the portions that still cannot be incorporated into IC's and in flexibly adjusting to the rapidly developing monolithic IC's as a supporting partner. The designers of electronic circuitry and planners of merchandise can be expected to utilize these advances in new HIC technology to create products having radically new capabilities and entirely new concepts of merchanise.

\section{CRITERIA FOR NEW HIC'S}

HIC techniques must be considered in the framework of a total systems technology. The electronic circuitry that constitutes the major internal portion of a final product consists of a very large number of electronic components and mechanical components of various types and also wiring and other materials. The manufacturers of these components are also numerous. Therefore, in trying to change or improve HIC components or introducing new production principles for HIC's, the methods must be readily acceptable by the industry and have a promising future. Also, after such HIC's are produced and used in merchandise, the product must be easily serviceable in case a component failure occurs. The criterion of serviceability is not glamorous but extremely important. For example, while automatic insertion machines have been highly recognized as a sophisticated production tool, the specifications of both the tapered parts and the machines have not been made adequately uniform among manufacturers. Moreover, the taped parts must share price increases, which present a problem. Another example is the serviceability of an HIC that includes not only transistors and IC chips but also capacitors and resistors in the shape of rectangular chips. Such a large-scale HIC is almost impossible to repair by a service technician or engineer, which there- 
fore poses the problem of service economy. Moreover, no systematic plan has been prepared for standardizing such a wide variety of chips.

It is believed that an HIC system must be developed that has a higher degree of completeness, but that such a matter must be considered as a total system that embraces the situation of manufacturers throughout the world that produce and market electronic circuitry.

\section{MELF COMPONENTS (THE NEW COMPONENTS WITHOUT LEAD WIRES)}

All types of two-terminal components made in a single shape (Figure 1) and uniformly applicable to specified conditions of use have been called MELF (Metal Electrode Facebonding) type components. The outer shape has been made cylindrical, because it is the inevitable shape to suit the new principles of HIC production, it is suited to the achievement of a wide range of uniformity, and it is the suitable shape for the production of tough, low-cost components.

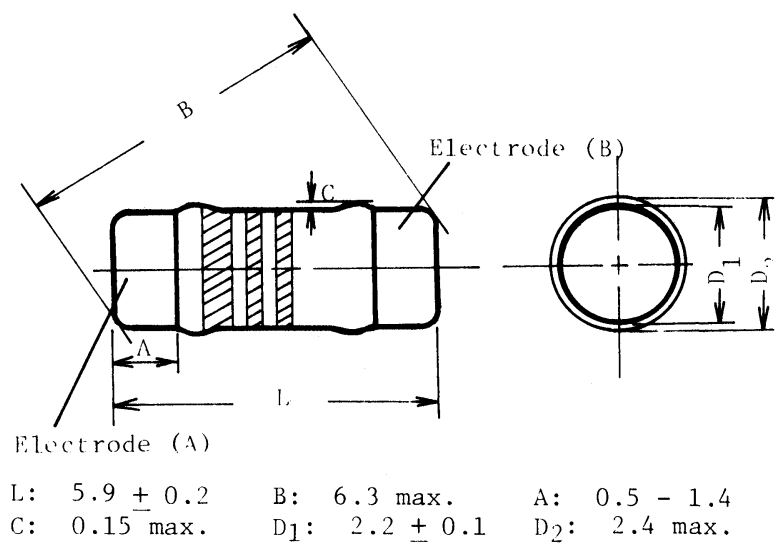

FIGURE 1 Dimensions of MELF components of uniform shape (in $\mathrm{mm}$ ) (Electrode (A) is either the cathode or positive polarity.)

The type of terminal that contributes to reliability is not lead wires or the metallic connections printed on the circuit board but the metal tips mechanically bonded on the component. They are resistant to heat, being able to withstand adequately the dipping of the terminals into a $250^{\circ} \mathrm{C}$ solder bath twice for 5 seconds at a time. (See Figure 2.) MELF components have either glass sleeves or resin protection between the electrodes (terminals). The protecting surface is color coded so that the type of component can be visually

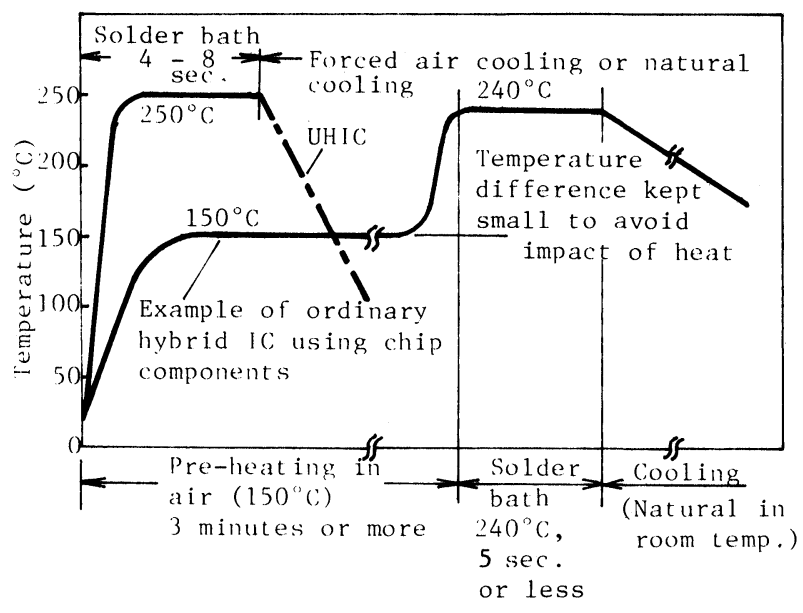

FIGURE 2 Comparison of soldering conditions for ordinary HIC's and UHIC's

determined easily. The color coding consists of three color stripes that represent the constants and other specifications of the component. The stripes are aligned towards one end of the cylinder, with the first stripe being wider than the other two, so that identification is facilitated. (See Photo 3.)

As MELF components can be produced in a wide variety of types (Table I), the major portion of components on a circuit board can be incorporated into UHIC assemblies. The component production can be speeded up, and the production facilities become interchangeable among component types.

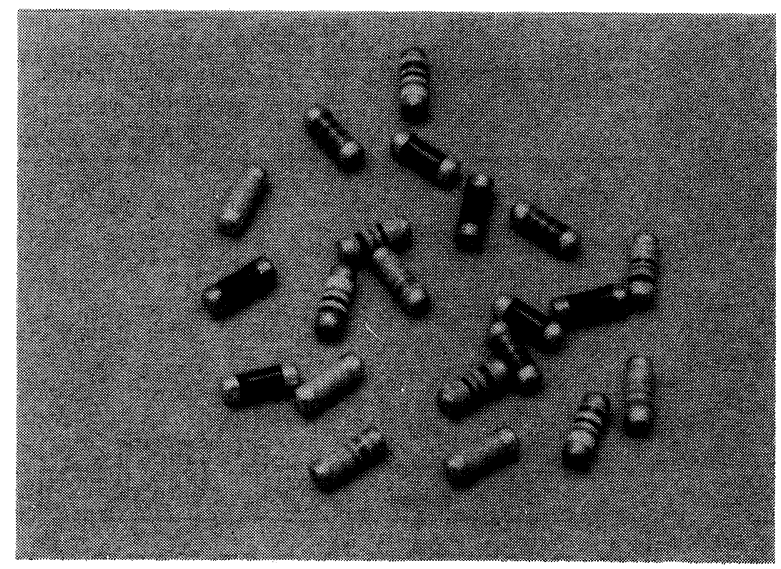

PHOTO 3 Various MELF components

\section{PRINCIPLE AND FEATURES OF UHIC'S}

The UHIC built mainly with MELF components has an assembly structure such as shown in Figure 3 which 
TABLE I

Specifications of MELF components having uniform outer shape.

\begin{tabular}{|c|c|c|c|}
\hline Type of component & Content & Polarity determination & Rating \\
\hline Ordinary resistor & $\begin{array}{l}\text { Ceramic cylinder, } \\
\text { carbon surface film, } \\
1.7 \phi \& 5.5 \mathrm{~mm} \text { length }\end{array}$ & None & $\begin{array}{l}1 \Omega-1 \mathrm{M} \Omega \pm 5 \%, \\
1 / 4 \mathrm{~W} \\
\mathrm{E}-24 \text { series }\end{array}$ \\
\hline High-grade resistor & $\begin{array}{l}\text { Ceramic cylinder, } \\
\text { metallic surface film, } \\
1.7 \phi \& 5.5 \mathrm{~mm} \text { length }\end{array}$ & None & $\begin{array}{l}10 \Omega-330 \mathrm{k} \Omega \pm 1 \% \\
1 / 4 \mathrm{~W} \\
\pm 50 \mathrm{ppm} \text { E- } 24 \text { series }\end{array}$ \\
\hline Fusing resistor & $\begin{array}{l}\text { Ceramic cylinder, } \\
\text { metallic surface film, } \\
1.7 \phi \& 5.5 \mathrm{~mm} \text { length }\end{array}$ & None & $\begin{array}{l}4.7 \Omega-470 \Omega \pm 5 \% \\
1 / 4 \mathrm{~W}, \mathrm{E}-24 \text { series } \\
\text { fusing } \mathrm{T} \leqq 20 \mathrm{sec}\end{array}$ \\
\hline Ceramic capacitor & $\begin{array}{l}\text { Ceramic cylinder, } \\
\mathrm{TiO}_{2} \text { or } \mathrm{SrTiO}_{3} \\
1.7 \phi \& 5.4 \mathrm{~mm} \text { length }\end{array}$ & None & $\begin{array}{l}1-1200 \mathrm{pF} \\
50 \mathrm{WV} \\
\pm 5 \%, \pm 10 \%, \pm 20 \%\end{array}$ \\
\hline $\begin{array}{l}\text { Semiconductor } \\
\text { ceramic capacitor }\end{array}$ & $\begin{array}{l}\text { Cyclinder, SrBL ceramic, } \\
1.8 \phi \& 5.4 \mathrm{~mm} \text { length }\end{array}$ & None & $\begin{array}{l}1500 \mathrm{pF}-0.022 \mu \mathrm{F} \\
50 \mathrm{WV}, 25 \mathrm{WV} \\
\pm 10 \%, \pm 20 \%, \pm 30 \%\end{array}$ \\
\hline Tantalum capacitor & $\begin{array}{l}\text { Cylindrical tantalum, } \\
\text { internal lead wires } \\
\text { welded }\end{array}$ & Magnetic determination & $\begin{array}{l}0.01-4.7 \mu \mathrm{F} \\
50 \mathrm{WV}, 25 \mathrm{WV}, 6 \mathrm{WV} \\
\text { E-6 series }\end{array}$ \\
\hline $\begin{array}{l}\text { Low power (high speed) } \\
\text { diode }\end{array}$ & Planar Si diode chip & Current flow & $\begin{array}{l}\mathrm{V}_{\mathrm{r}} \geqq 90 \mathrm{~V} \\
\mathrm{I}_{\mathrm{f}}(\max .)=0.1 \mathrm{~A} \\
\mathrm{I}_{\mathrm{p}}(\max .)=1 \mathrm{~A}\end{array}$ \\
\hline Zener diode & Planar Si diode chip & Current flow & $\begin{array}{l}P_{c}(\max .)=0.4 \mathrm{~W} \\
V_{z}: 5-35 \mathrm{~V}\end{array}$ \\
\hline Power diode & Planar Si diode chip & Current flow & $\begin{array}{l}\mathrm{V}_{\mathrm{r}} \geqq 100 \mathrm{~V} \\
\mathrm{I}_{\mathrm{f}}(\max .)=0.3 \mathrm{~A} \\
\mathrm{I}_{\mathrm{p}}(\max .)=5 \mathrm{~A}\end{array}$ \\
\hline Bridge conductor & $\begin{array}{l}\text { Ceramic cylinder, } \\
\text { metallic surface film, } \\
1.7 \phi \& 5.5 \mathrm{~mm} \text { length }\end{array}$ & None & $\begin{array}{l}\text { Internal } \mathrm{R}<5 \mathrm{~m} \Omega \\
\mathrm{I}(\max .)=5 \mathrm{~A}\end{array}$ \\
\hline
\end{tabular}

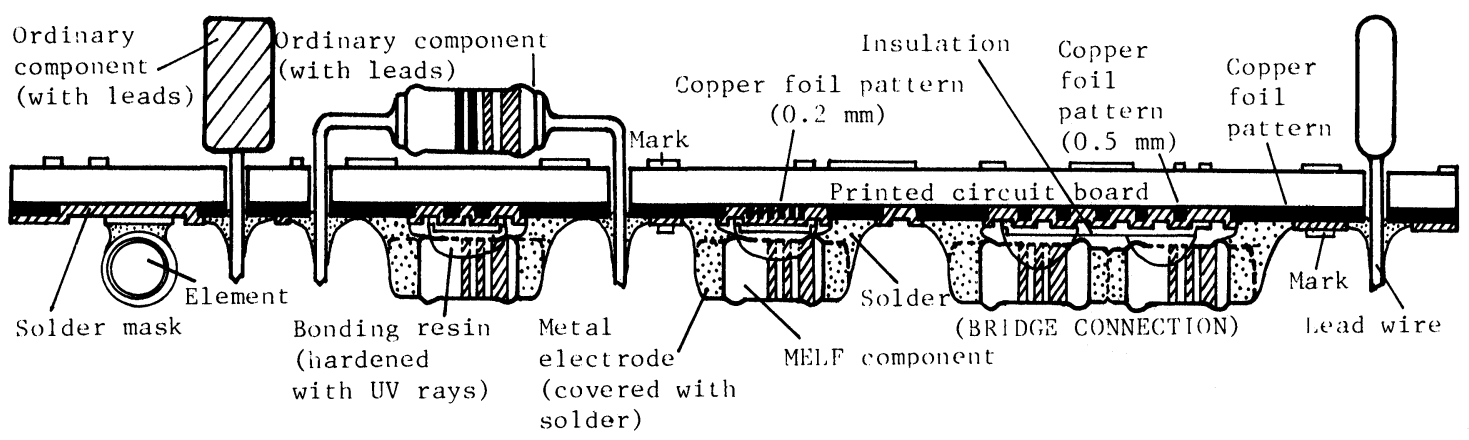

FIGURE 3 
results from the process outlined in Figure 4. In the production process of the printed circuit board, a copper foil 35 microns in thickness is bonded to the phenol resin or epoxy resin substrate and chemically etched into the required circuit pattern. As in the case of the usual printed circuit board, the greater the circuitry, the greater is the required precision, which therefore necessitates computer aided design. The process for mounting components is very simple. Because it is necessary to adhere the components to the board with resin, a thickness of 300 to 400 microns of resin is screen-printed on the spots where the MELF components are to be placed. Several hundreds of MELF components are then arranged over the circuit board simultaneously in their proper locations, fed from hoppers supplying the components (Photo 4). Diodes and tantalum capacitors or other components that must be

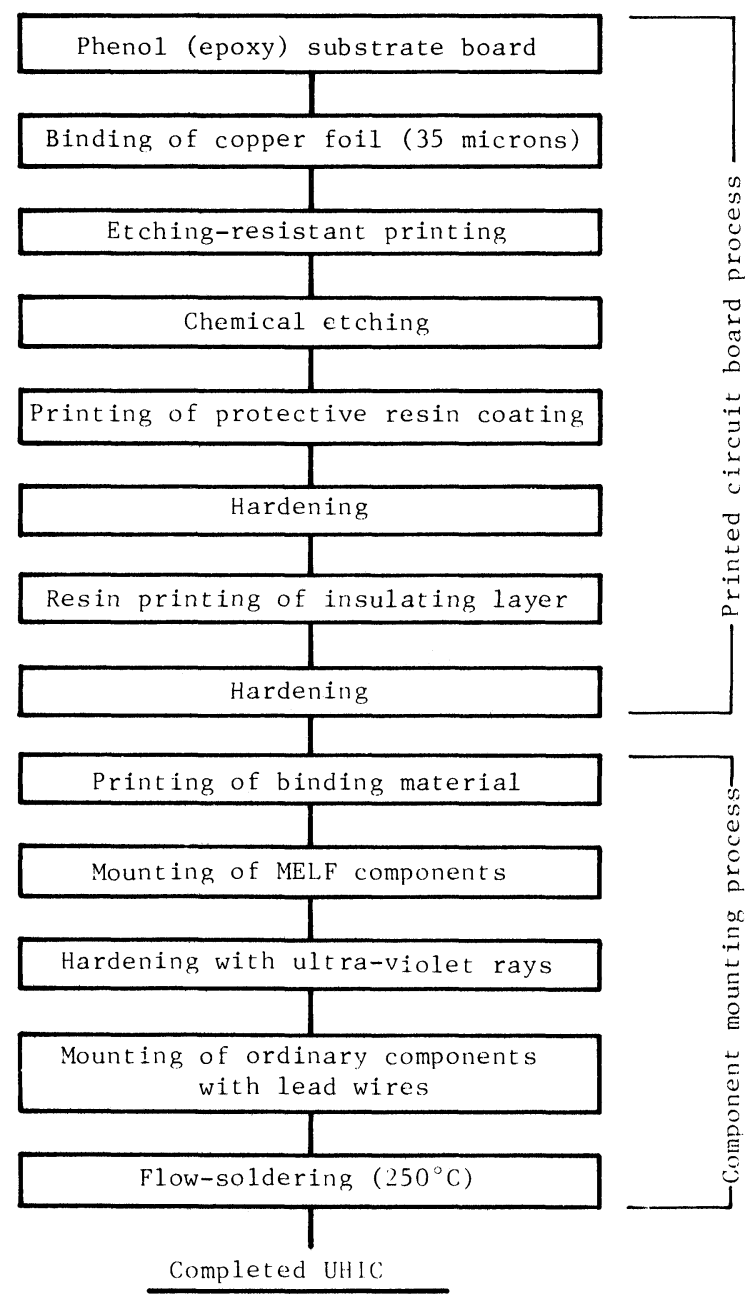

FIGURE 4 Diagram of UHIC production process

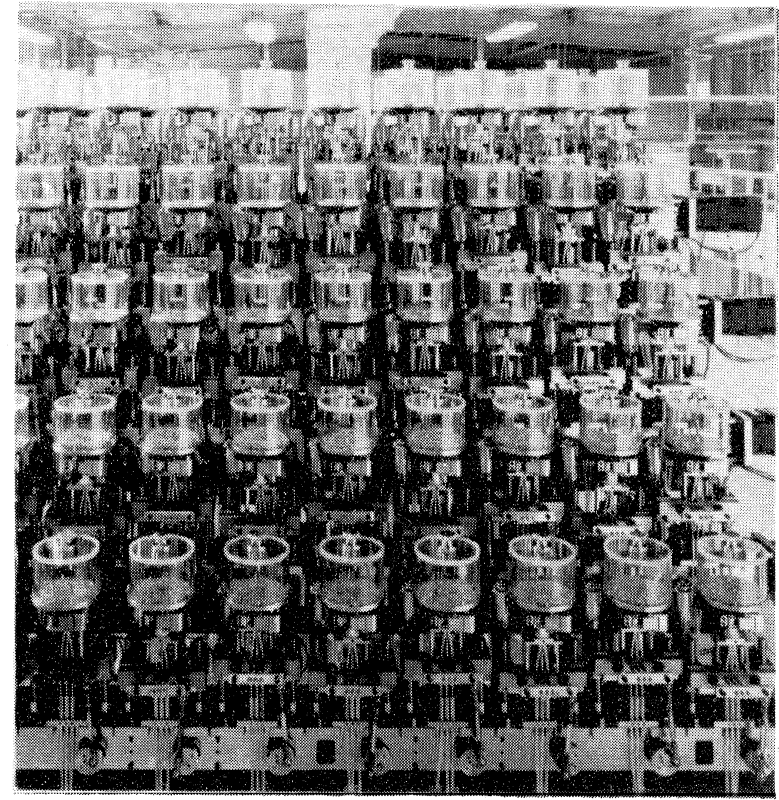

PHOTO 4 MELF component feeder employing hoppers. (This machine has 100 hoppers holding 50,000 components/hopper.)

arranged with their polarity properly aligned are unerringly set in their correct alignment at the supply hopper units. The resin that holds the components in position on the board is then hardened. In the present process, the hardening takes place under ultra-violet rays. The reason for using ultra-violet rays is that heat-hardening causes oxidation of the copper foil circuit pattern, thus reducing the reliability of the soldering and also reducing the adhesive strength of the resin.

A more detailed explanation follows, with reference to Figure 5. When the component is placed on the board and pressed from above, the resin clings around the body of the component as shown in [B]. The resin holds the component over an angle $\phi_{1}$ as shown in [C] (a). If the resin is hardened with ultra-violet rays the angle $\phi_{1}$ is maintained in the hardened state of the resin. However, if heat-hardening is employed, the resin softens and flows a bit before hardening, reducing the holding angle to $\phi_{2}$ as shown in [C] (b). Components properly adhered to the board by ultra-violet hardening of the resin are firm enough to withstand forces of over 4 to 5 kilograms before they can be pulled off. Other components having the usual lead wires are next inserted on the board by an automatic insertion machine. Mechanical parts, such as switches and volume controls, are also inserted. The entire board thus assembled is then sent through a flow-solder 


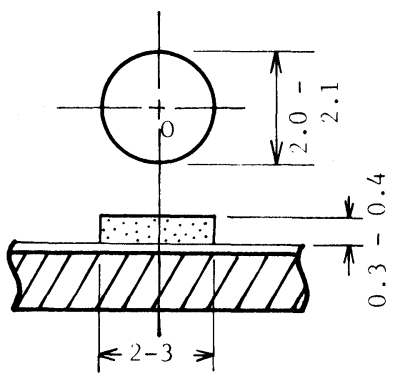

[A] Binding resin printed (in mm)

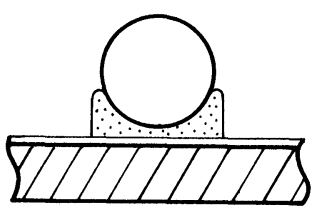

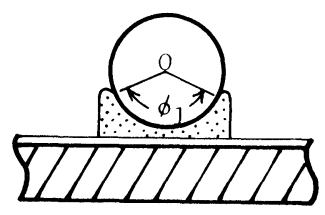

(a) Hardening with UV rays (Resin covers initial area or surface.)

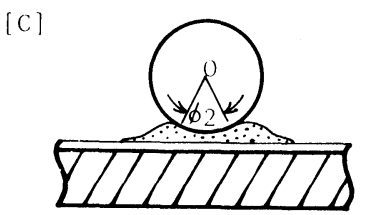

(b) Hardening with applied heat (Resin first softens and spreads before hardening.
FIGURE 5 Hardened state of the binding resin

treatment in the usual manner, and the MELF components are firmly soldered in one operation.

Photo 5 shows a portion of a large UHIC processed in this way. Photo 6 shows a cross-section of a resistor

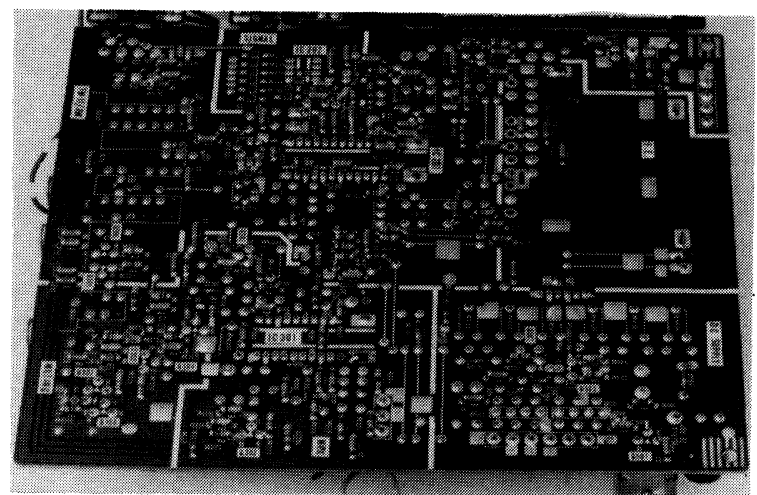

PHOTO 5 “All-in-one" UHIC type assembly produced in 1979 for ST-535 FM/AM tuner

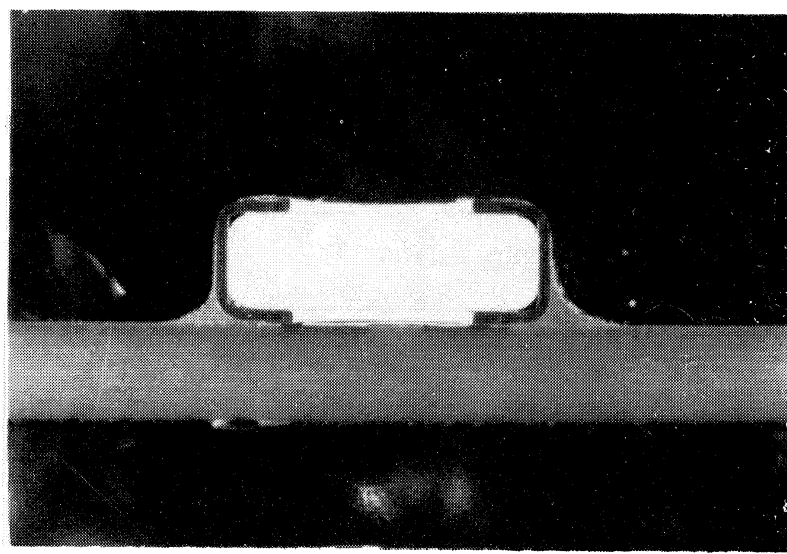

PHOTO 6 Cross section of MELF resistor bonded with solder on a phenol printed circuit board

soldered in this manner, which displays the round-face bonding unique to this system. Since the MELF component electrodes are soldered under the same conditions as the soldering of components with lead wires, the reliability of the soldering of the entire board is greatly increased. Moreover, this soldering process is interchangeable with flow soldering units used for ordinary circuit boards.

\section{UHIC PRODUCTION SYSTEM}

Two systems have been successfully put into operation to produce UHIC's. One is the Sony synchromatic wiring system (SSWS) which is shown in Photo 7. The

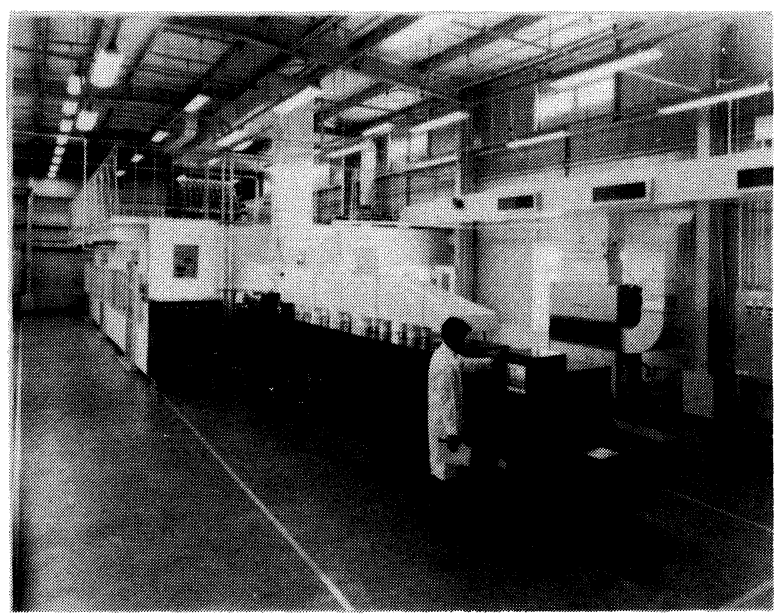

PHOTO 7 Automatic production system for UHIC's (SSWS-A type) in 1979 
TABLE II

Specifications of automatic production system for UHIC's (SSWS-A).
Max. outer dimension of board

Number of components mounted simultaneously

Machine cycle

Equivalent per unit speed of mounting

Component feeding method

Number of components per hopper

Directions of component alignment

Machine operating noise

Soldering method

Mountable components

Conversion time for changes in product model
Number of direct operators checking procedures for mounting and different methods of carrying, depending on the shape of the components. The conventional automatic insertion machines have increased the work load of parts manufacturers. MELF components have markedly reduced the number of checks needed for automation purposes. Rectangular chips are hexahedrons, which therefore require three types of mounting information to be checked. Moreover, in order to transmit this information to the automatic production machine, it is necessary to employ special carrying methods, such as magazines and tape carriers. Also, since there is no method of identifying the component, mistakes in operation can occur in the actual process, which means that preventive controls become critical.

40 phons or less direct flow soldering ( 4 to $5 \mathrm{sec}$. at $250^{\circ} \mathrm{C}$ )

2 or 3 ( 1 or less in future) MELF components with or without polarity

15 to 30 minutes specifications of this system are listed in Table II. The second system is called the Sony sequential MELF-components placer (SSMP), which is used for trial production and production in small quantities.

These systems were the result of the effective utilization of MELF-type component features. As shown in Figure 6, the various types of existing components designed for automatic mounting require different

\section{RELIABILITY AND SERVICEABILITY}

The number of elements integrated into a single chip in monolithic IC's has been increasing rapidly. This trend has continued with the aim of reducing the production cost of high-density circuitry. It would be meaningless, if the reliability were to decrease with this trend. If HIC's are increasingly integrated, the production cost would naturally be reduced. However, such an HIC mounted with mechanical parts and other various types of components will bring the cost of a single completed board up to a hundred or thousand times the unit cost of a component. The feasibility of repairs thus becomes an extremely important problem.

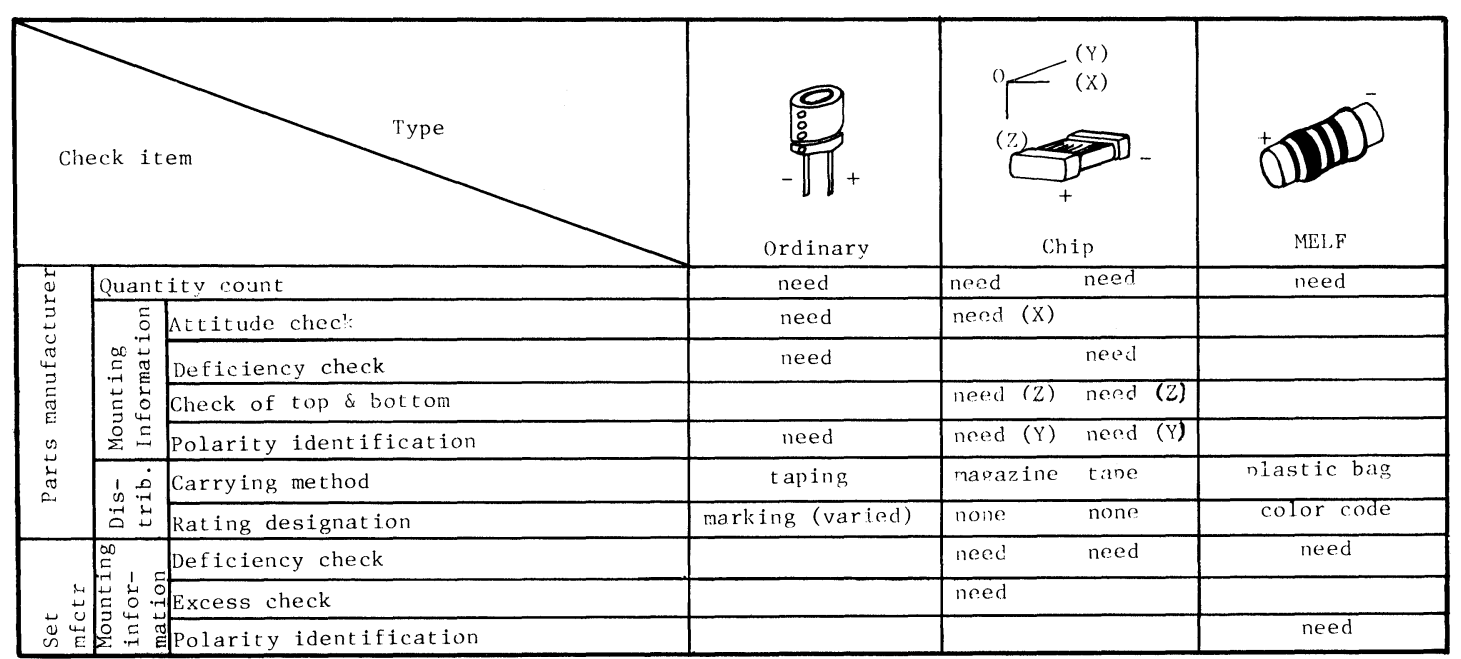

FIGURE 6 Checks needed for components with polarity. (Among chip components, transistors and diodes have type designations.) 


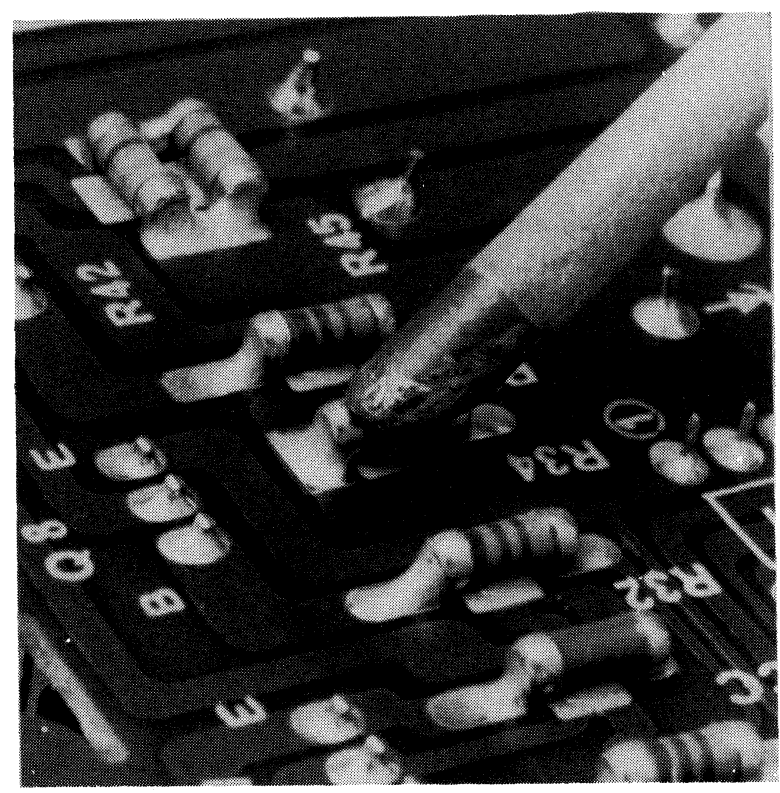

PHOTO 8 Method of removing MELF component: By applying a soldering iron, about $4 \mathrm{~mm}$ in diameter, on top of the component for about 5 to 6 seconds, as shown above, the solder and adhesive resin are softened so that the component is easily removed.

The firmness of UHIC components is one of the important features resulting from the large soldering area achieved through face bonding. While this greatly improves reliability, an occasional replacement of a component may become necessary. As shown in Photo 8 , the MELF component can be removed with a soldering iron in about half the time required for ordinary components. After the MELF component is removed, a new MELF component or an ordinary component having leads can be soldered back in place to complete the repair. This means that existing service systems require no changes to handle the new UHIC boards.

\section{CONCLUSION}

It is believed that the UHIC system is the desirable next generation of HIC's following the present automatic insertion machine era. This desirability is based on several reasons: A wide range of components can be produced in the same uniform shape, which should allow broad standardization. The outlook is promising for further development of high-grade components in this format. A radically new mounting system has been created with these components, resulting in great increases in productivity. Repairs are easy with the system, even though very large scale HIC's are assembled, which provides economic advantages. Also, the era seems to have arrived where UHIC technology can be applied as the next step after manual insertion work, without having to go through an intermediate stage of employing automatic insertion machines. 

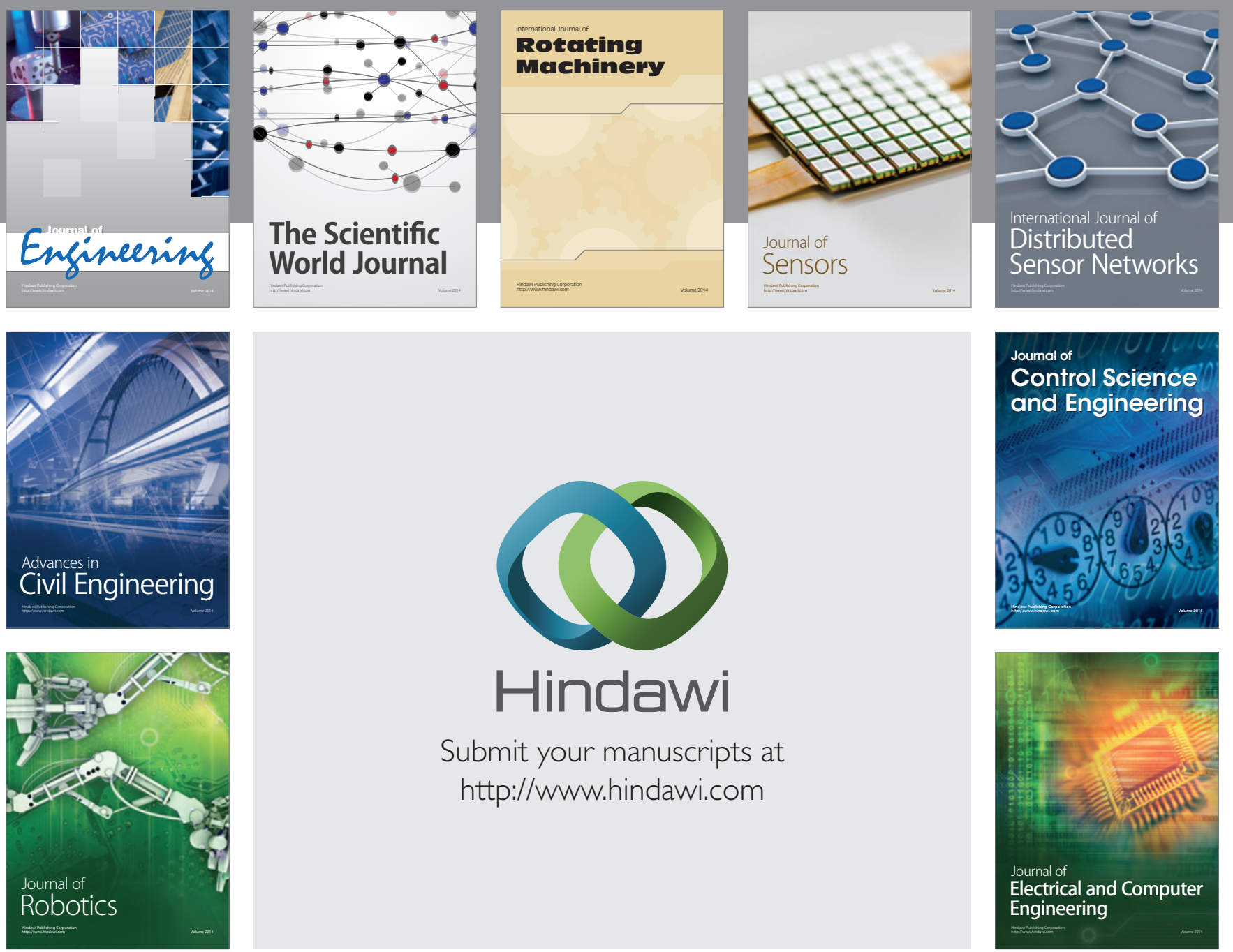

Submit your manuscripts at

http://www.hindawi.com
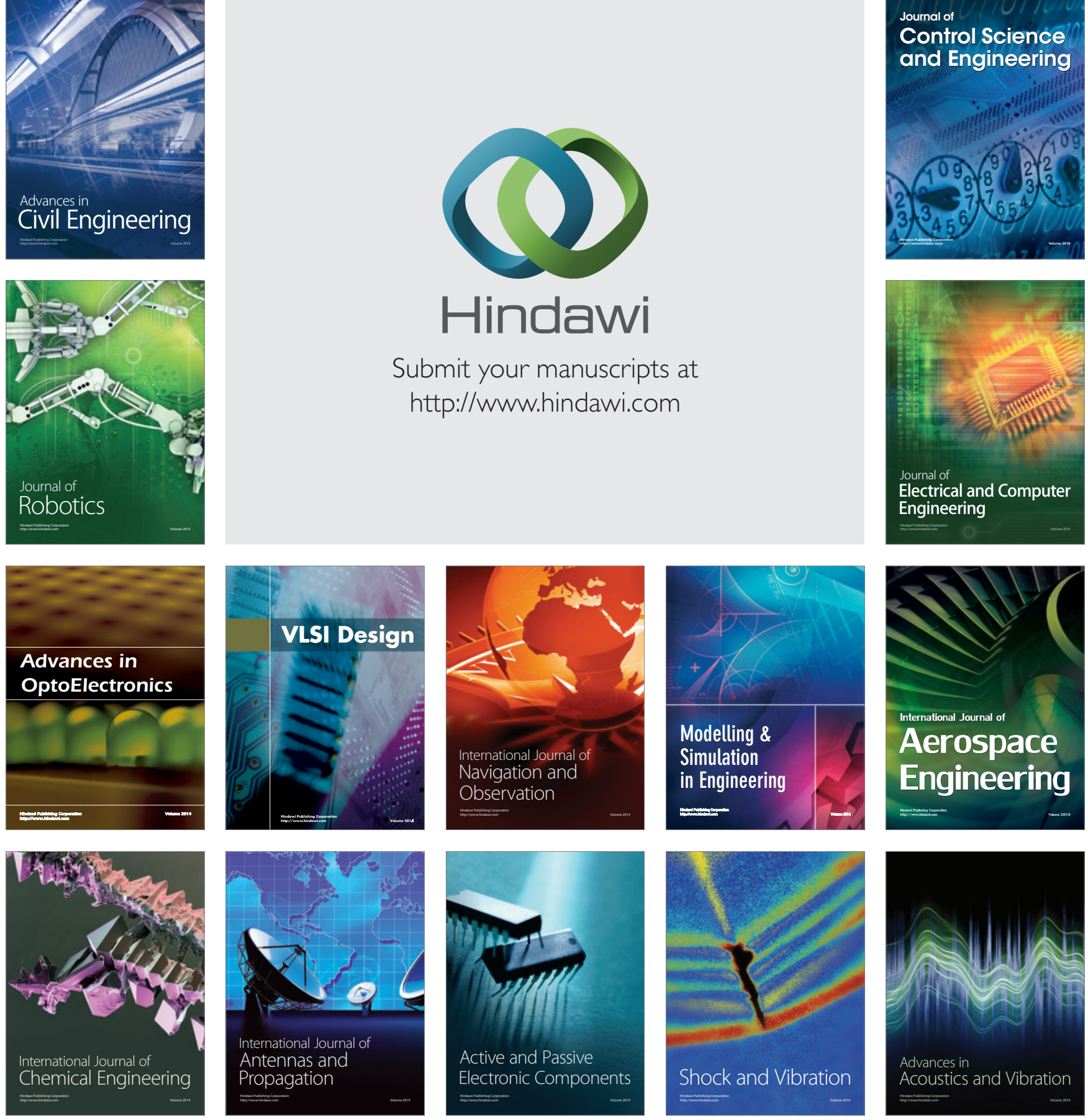